\title{
CLINICAL PROFILE OF DERMATOPHYTOSES IN NORTH KERALA
}

\author{
${ }^{1}$ Associate Professor, Department of Microbiology, Government T.D. Medical College, Alappuzha. \\ 2Junior Resident, Department of Microbiology, Government Medical College, Calicut. \\ ${ }^{3}$ Associate Professor, Department of Microbiology, Government T.D. Medical College, Alappuzha. \\ ${ }^{4}$ Senior Scientific Assistant, Department of Microbiology, Government Medical College, Calicut. \\ 5 Professor and HOD, Department of Microbiology, Government Medical College, Calicut.
}

Mini Palathingal Narayanan1, Sreeja Illathukandy², Vimalraj Angattukuzhiyil Narayanan³, Asokan Kuttiyil', Remadevi Surendren ${ }^{5}$

\section{ABSTRACT}

\section{BACKGROUND}

Dermatophytosis is the most common superficial fungal infection of the keratinised tissues like skin, hair and nail. The present study was aimed to determine the clinical pattern of dermatophytes in North Kerala and the common species prevalent in the area.

\section{MATERIALS AND METHODS}

Laboratory and clinical data of the patients with cutaneous infection were collected and subjected to standard mycological techniques.

\section{RESULTS}

A total of 130 samples were taken, 61(47\%) showed positive culture. Tinea corporis $52(28 \%)$ was the commonest clinical type. Trichophyton rubrum 35 (57.5\%) was the predominant species isolated.

\section{CONCLUSION}

The prevalence of dermatophytosis varies with geographical location and the age group affected. The aetiological agents also depend upon the site of infection and various factors.

\section{KEYWORDS}

Dermatophytes, Superficial Mycosis, Keratinised Tissue, Sabouraud Dextrose Agar.

HOW TO CITE THIS ARTICLE: Narayanan MP, Illathukandy S, Narayanan VA, et al. Clinical profile of dermatophytoses in North Kerala. J. Evolution Med. Dent. Sci. 2016;5(87):6461-6465, DOI: 10.14260/Jemds/2016/1461

\section{BACKGROUND}

Although fungi are present worldwide, only a few of them are considered pathogenic. The pathogenic fungi give rise to infections in animals and human beings. Dermatophytes are the major agents of superficial mycoses of man and are a general public health problem. It is more prevalent in tropics, and may reach epidemic proportions in areas where high rate of humidity, overpopulation and poor hygienic conditions. Thus, this study was undertaken with an aim to find out various clinical patterns, mycological aspects and also to identify the species of dermatophytes prevalent in this part of country.

Recently, there has been an increase in the incidence of fungal infections. This increase may be a result of frequent usage of antibiotics, immunosuppressive drugs and various conditions like organ transplantations, lymphomas, leukaemia and human immunodeficiency virus (HIV) infections. ${ }^{1}$ Infection due to dermatophytes has become a significant health problem affecting children, adolescents and adults.

Financial or Other, Competing Interest: None.

Submission 23-09-2016, Peer Review 17-10-2016,

Acceptance 24-10-2016, Published 28-10-2016.

Corresponding Author:

Dr. Mini Palathingal Narayanan,

Associate Professor

Department of Microbiology,

Government T. D. Medical College,

Alappuzha-688005,

Kerala.

E-mail:mini_pn@rediffmail.com

DOI: $10.14260 /$ jemds $/ 2016 / 1461$
A correct diagnosis is important to initiate appropriate treatment and also essential for epidemiological purposes. The term dermatophyte literally means 'plant growing on the skin' being derived from the words 'dermatos'= skin, 'phytos'= plant. ${ }^{2}$

Dermatophytes are amongst the earliest microorganisms that were found to cause human infection as early as 1841 . The ancient Greek physicians knew about ring worm infections. Dermatophytes invade the stratum corneum of the skin or other keratinised tissues derived from epidermis such as hair and nails. They cause the most common types of cutaneous fungal infections seen in man and animals affecting almost all sites but mainly skin, hair and nails. The infection is dermatophytoses, commonly known as ring worm or tinea. Recently, few cases of subcutaneous and deep fungal infections are also caused by dermatophytes, especially in the immunocompromised, if the fungi invade subcutaneous tissue via lymphatics leading to granulomas, lymphoedema and draining sinuses. Rarely, other sites including liver and brain also may be affected. ${ }^{3}$

Identification of dermatophytes is important to understand the spread of infection, especially those producing institutional or family outbreaks. The dermatophytes are a group of closely related fungi that have the capacity to invade keratinous tissue (skin, hair, nails,) of humans and lower animals. They are by far the most significant fungi because of their widespread involvement of population at large and their prevalence all over the world. The identification of majority of pathogenic fungi still relies largely on direct observation of their morphology. Species 
identification is largely based on the morphology and arrangement of conidia.

\section{MATERIALS AND METHODS}

\section{Aims and Objectives}

The present study was done to find out the clinical profile of dermatophytoses and the common species of dermatophytes prevalent in North Kerala. It was done by collecting laboratory and clinical data from patients attending Dermatology and Microbiology Department of Govt. Medical College, Kozhikode during (2010, January -December). Patients with infections of skin, nail and hair clinically suggestive of dermatophytoses were included in the study. The clinical specimens aseptically collected for the study were: Skin scraping or nail clippings taken from the active margin of the lesions after cleaning with alcohol, with sterile blade on to a black paper. Clippings were taken from appropriate site depending on the type of nail infection. Hair stubs were taken from the basal root portion of hair by plucking.

Direct microscopic examination was done by wet mount preparation with Potassium Hydroxide $(\mathrm{KOH})$; Nail clipping was kept in $20 \% \mathrm{KOH}$ overnight, before microscopic examination.

The skin scrapings were placed on clean glass slide and $10 \% \mathrm{KOH}$ (Potassium Hydroxide) added, and examined for hyphae and arthrospores. The nail specimens were examined after keeping for 24 hours.

In a positive preparation, the fungi appeared as septate branching hyphal elements, highly refractile among the epidermal scales. The specimens were inoculated into Sabouraud Dextrose Agar (SDA) with and without antibiotics. Antibiotics included chloramphenicol and Cycloheximide. Corn meal agar with $1 \%$ glucose was used to detect pigment production and to produce better sporulation. The tubes were incubated at room temperature for 4 weeks. If there was no growth after 4 weeks, the culture was considered negative. The species identification was done by microscopic examination of microconidia, macroconidia and hyphal arrangement. Identification of the fungus was done by noting the rate of growth, gross morphology of the colony on SDA pigmentation on the reverse, and by microscopic morphology in Lactophenol Cotton Blue (LCB) mount noting the diameter of hyphae, septa and arrangement of conidia. The other methods done were slide culture and adhesive (scotch) tape preparation. Other nutritional requirement tests also were done like hair perforation test and urea hydrolysis test.

\section{RESULTS}

Total number of cases included in the study was 130. All these cases underwent clinicomycological evaluation. The youngest patient was an 11-month-old female baby. She presented with tinea corporis affecting the buttocks and lower back. The oldest patient was 78 years of age and presented with tinea unguium affecting the toes. The largest number of dermatophyte infections were seen in the age group 16-30. There were 36 cases (27.69\%). Minimum number of cases were seen in age group above 70 years ( 4 cases, $3.08 \%$ ).

\begin{tabular}{|c|c|c|}
\hline Age Group (Yrs.) & Number & Percentage \\
\hline $0-15$ & 18 & 13.8 \\
\hline $16-30$ & 36 & 27.69 \\
\hline $31-40$ & 21 & 16.15 \\
\hline $41-50$ & 30 & 23.08 \\
\hline $51-60$ & 9 & 6.9 \\
\hline $61-70$ & 12 & 9.2 \\
\hline$>70$ & 4 & 3.08 \\
\hline Total & $\mathbf{1 3 0}$ & $\mathbf{1 0 0}$ \\
\hline
\end{tabular}

Table 1. Distribution According to Age Group [n =130]

Out of 130 cases, 81 cases were males (63.08\%), and females were $49(36.92 \%)$. The male to female ratio was 1.71:1.

\begin{tabular}{|c|c|c|}
\hline & Number & Percentage \\
\hline Males & 81 & 63.08 \\
\hline Females & 49 & 36.92 \\
\hline Total & $\mathbf{1 3 0}$ & $\mathbf{1 0 0}$ \\
\hline \multicolumn{2}{|c|}{ Table 2. Distribution According to Sex [n=130] } \\
\hline
\end{tabular}

In this study, manual labourers constituted the majority of cases i.e. 52 (40\%) patients.

\begin{tabular}{|c|c|c|}
\hline & Number & Percentage \\
\hline Manual labourers & 52 & 40 \\
\hline Students & 29 & 22.31 \\
\hline Housewives & 25 & 19.23 \\
\hline Others & 24 & 18.46 \\
\hline Total & 130 & 100 \\
\hline
\end{tabular}

\begin{tabular}{|c|c|c|}
\hline Clinical Types & Number & Percentage \\
\hline Tinea corporis & 52 & 40 \\
\hline Tinea cruris & 29 & 22.3 \\
\hline Tinea capitis & 4 & 3.07 \\
\hline Tinea unguium & 19 & 14.6 \\
\hline Tinea pedis & 5 & 3.84 \\
\hline Tinea manuum & 2 & 1.53 \\
\hline Tinea faciei & 1 & 0.76 \\
\hline Mixed & 18 & 13.84 \\
\hline Total & 130 & 100 \\
\hline
\end{tabular}
(47\%).

Out of 130 cases, 61 patients showed positive culture

\begin{tabular}{|c|c|c|}
\hline & Number & Percentage \\
\hline Culture positive & 61 & 47 \\
\hline Culture negative & 69 & 53 \\
\hline Total & 130 & 100 \\
\hline
\end{tabular}




\begin{tabular}{|c|c|c|c|c|c|c|c|}
\hline $\begin{array}{c}\text { Clinical Types } \\
\text { N-Number }\end{array}$ & $\begin{array}{c}\mathrm{T} . \\
\text { rubrum }\end{array}$ & $\begin{array}{c}\text { T. } \\
\text { mentagrophytes }\end{array}$ & $\begin{array}{c}\text { E. } \\
\text { floccosum }\end{array}$ & T. tonsurans & M. canis & T. verrucosum & Culture Positive \\
\hline $\begin{array}{c}\text { Tinea corporis } \\
n=52\end{array}$ & 19 & 7 & & & 1 & 1 & 28 \\
\hline $\begin{array}{c}\text { Tinea cruris } \\
\mathrm{n}=29\end{array}$ & 5 & & 4 & & & & 9 \\
\hline $\begin{array}{c}\text { Tinea capitis } \\
n=4\end{array}$ & & 1 & & 1 & & & 2 \\
\hline $\begin{array}{c}\begin{array}{c}\text { Tinea unguium } \\
n=19\end{array} \\
\end{array}$ & 3 & 7 & & 1 & & & 11 \\
\hline $\begin{array}{c}\text { Tinea pedis } \\
n=5\end{array}$ & 1 & 1 & & & & & 2 \\
\hline $\begin{array}{c}\text { Tinea manuum } \\
n=2\end{array}$ & 1 & & & & & & 1 \\
\hline $\begin{array}{c}\text { Tinea faciei } \\
n=1\end{array}$ & & & & & & & 0 \\
\hline $\begin{array}{l}\text { Mixed } \\
\mathrm{n}=18\end{array}$ & 6 & 2 & & & & & 8 \\
\hline $\begin{array}{c}\text { Total } \\
\mathbf{n}=130\end{array}$ & $\begin{array}{c}35 \\
57.5 \% \\
\end{array}$ & $\begin{array}{c}18 \\
29.5 \% \\
\end{array}$ & $\begin{array}{c}4 \\
6.5 \% \\
\end{array}$ & $\begin{array}{c}2 \\
3.5 \% \\
\end{array}$ & $\begin{array}{c}1 \\
1.5 \% \\
\end{array}$ & $\begin{array}{c}1 \\
1.5 \% \\
\end{array}$ & $\begin{array}{c}61 \\
100 \%\end{array}$ \\
\hline
\end{tabular}

\section{DISCUSSION}

In this study out of 130 cases evaluated, the highest number of cases were found in the age group 16-30 (27.69\%). Kamothi et al noted maximum number of patients in the third decade in the age group of 21 - 30 years. ${ }^{4}$ Bindu et al from Calicut found maximum number of cases in the age group 1120 years $^{5}$ showing similar results as that of the other studies $6,7,8$ whereas other earlier studies from Calicut showed maximum number of cases in the third decade. ${ }^{9}$

The youngest patient in our study was an 11-month-old female baby who presented with annular type of tinea corporis over the buttocks and lower back. The youngest age of onset documented in the literature by culture is two days of age. ${ }^{10}$ Compared with our series, this difference may be due to relatively less number of infant cases involved in the study. The oldest patient was 78 years of age with tinea unguium involving the toes. The incidence of dermatophytes was lowest in age group above 70 years in our study which was quite similar to other studies. ${ }^{11}$

In this study, it was observed that males were more commonly affected than females. The male: female ratio in our study was 1.71:1. Most of the workers have observed that the male to female ratio ranged from $1.5: 1$ to $3: 1,12$ while Kamothi et al reported a male to female ratio of 2.03:1.13

Tinea cruris is considered more common in men. This could be due to more occlusive clothing, greater physical activity, greater occlusion around scrotum and high incidence of dermatophytic infection in males which act as a reservoir. ${ }^{13}$ Tinea cruris was observed to be higher in males in our study, with males 18 (62.06\%), and females 11 (37.9) out of 29 total cases. The lower incidence of tinea cruris in females in the study could partly be due to unwillingness to reveal the lesion in crural region. Tinea corporis was slightly more in females (53.84\%) compared to males in our study (47.26\%). This could be due to more incidences of tinea corporis affecting the waist area and upper trunk due to wearing of tight under garments and sarees.

Manual labourers were found to contribute to majority of the cases (40\%). This could be explained by the role of trauma and extensive sweating that invites infection. $66 \%$ of patients were found to be from lower socioeconomic strata. Sentamilselvi et al also showed that most of the patients belonged to a poor socioeconomic status, ${ }^{14}$ correlating with our study. The reason behind this may be the living style, large size of the family and close contact among the members, either directly or by sharing facilities like combs and bath towels.

Among the 130 cases enrolled in the study, most common clinical type was tinea corporis $(40 \%)$ followed by tinea cruris $(22.3 \%)$. This is in concordance with various other studies. ${ }^{15}$ Parallel findings were noted in the series of Bindu et al who reported tinea corporis as major clinical type followed by tinea cruris. ${ }^{5}$ A study in Calicut by Maheswari Amma et al also found tinea corporis as the commonest one. ${ }^{9}$

Tinea capitis was observed in 4 patients below the age of 15. Tinea capitis should be considered in the diagnosis of any child over the age of 3 months with a scaly scalp until ruled out by negative mycology.16 Tinea capitis was the predominant dermatophytosis in children was also as found out by Kamothi et al. ${ }^{13}$ Tinea capitis is predominantly a disease of pre-adolescent children. ${ }^{17}$

Among the children affected with tinea capitis more incidence is seen in male children. In our study, all tinea capitis cases were seen in male children. Rippon postulated that high incidence of tinea capitis in male children could be due to short hair in boys allowing excess implantation of spores. ${ }^{18}$ The reason for rarity of tinea capitis in adults is thought to be due to increase in fungicidal and fungistatic fatty acids in sebum, protection afforded by the scalp colonisation by Pityrosporum orbiculare and other unidentified immunological mechanism. ${ }^{19,20}$ In our study out of the four tinea capitis cases, two were of grey patch type and one each of black dot and kerion type. Two out of four tinea capitis also had cervical lymphadenopathy in our study.

Tinea unguium was found in $14.66 \%$ of patients in our study. A similar study by Bindu et al found almost similar incidence of $13.3 \% .^{5}$ The incidence of tinea unguium is more common in males compared to females in our series (11 males and 8 females). This may be due to increased physical activity in males which increases the chance of trauma and fungal invasion. Bindu et al also reported higher incidence of tinea unguium in males. ${ }^{5}$ The most common type of tinea unguium reported in our study was distal and lateral 
subungual type. Sofia et al also reported the same type as the commonest one. ${ }^{21}$

Tinea pedis was seen in $3.84 \%$ of patients in our study. This was similar to that reported by Sofia et $\mathrm{al}^{21}$ and Bindu et al. ${ }^{5}$ But in contrast, the incidence of tinea pedis in the study by Kamothi et al was $13.5 \%{ }^{4}$ Tinea pedis was also more common in males ( 3 in males and 2 in females) in our study. The risk of tinea unguium and tinea pedis is higher in men than in women and also increased with age in the case of tinea unguium. ${ }^{8}$ The increased prevalence of tinea unguium and tinea pedis in men compared to that in women could be the result of trauma and the common use of occlusive footwear which favours the appearance of both diseases. Sofia et al also reported a higher incidence of tinea pedis in males ${ }^{22}$ and also by Bindu et al. 5 Our study showed that tinea unguium affected elderly people commonly. The increased prevalence of tinea unguium in the elderly members of the population could be explained as a consequence of nail trauma and slow nail growth.

In our study, tinea faciei was seen in $0.76 \%$ patients. This was similar with that reported by Kamothi et al.13 $13.8 \%$ of patients in the present study had mixed type of infections and $86.2 \%$ had single infection.

Itching was the most common symptom noted in $79.2 \%$ patients. $66.11 \%$ of cases revealed that there is associated increased sweating. This correlates well with the results of Bindu et al. ${ }^{5}$ Most of the patients had symptoms of less than 3 months duration and about $45 \%$ presented with recurrent episode.

$20 \%$ of patients gave a history of involvement of family members in the present study. This could act as a source of infection. History of contact with infected family members was seen in $3.09 \%$ in study by Kamothi et al while Bindu et al noticed $16.6 \%$ in her study. 13,5 Four patients gave a history of contact with pet animals. This can also act as a source of infection either through direct or indirect contact. ${ }^{22}$

Diabetes mellitus was the most common disease found to be associated (13.1\% cases). Jolly and Carpenter in 1969 reported the significance of uncontrolled blood glucose level in dermatophytic infections. ${ }^{23} \mathrm{~A}$ study from South India also showed that diabetes mellitus was the risk factor for dermatophytic infection. ${ }^{15}$ Atopy was seen in 8 patients $(6.15 \%)$ in our study. It has been shown that atopic dermatitis is a risk factor for chronic Trichophyton rubrum infection. ${ }^{24}$ Bindu et al also reported higher rate of dermatophyte infections in diabetics and atopics. ${ }^{5}$ In our study, 3 patients $(2.5 \%)$ had HIV infection. Out of these, one patient presented with proximal subungual type. Proximal subungual type is described as an indicator of acquired immunodeficiency syndrome. ${ }^{25}$ There was one patient with renal transplant in our study. Dermatophytosis was detected in $42 \%$ of 100 renal transplant recipients screened in a study. ${ }^{26}$

The overall culture positivity was $46.92 \%$ (61 out of 130 ) in our study. Various other studies showed the positive culture over a range of $11-78 \% .^{7}$ The overall positivity by culture was 45.3 in the study by Bindu et al. ${ }^{5}$ The positive culture was $48.5 \%$ in the series of Kamothi et al. ${ }^{13}$ In fungal culture, Trichophyton rubrum was the commonest species isolated (35 out of 61 positives $-57.37 \%$ ) and the second commonest was Trichophyton mentagrophytes (18 cases $29.5 \%$ ). This is correlating with various other studies which showed a higher prevalence of Trichophyton rubrum.7 Trichophyton rubrum can persist in body for longer duration. This is due to special characteristics of Trichophyton rubrum such as induction of immunological unresponsiveness, affinity for keratin of palms and soles, nails, suppression of CMI, greater invasiveness and spore formation outside the body. 27

Epidermophyton floccosum was obtained in $6.5 \%$ of culture positive cases. One Trichophyton verrucosum found in a tinea corporis patient. Out of the two positive tinea capitis cases, one case each of Trichophyton mentagrophytes and Trichophyton tonsurans was obtained. T. tonsurans was reported as the main causative pathogen in tinea capitis in a study by Williams et al. ${ }^{28}$

\section{CONCLUSION}

Out of 130 patients studied, $63.08 \%$ were males and $36.92 \%$ were females. The highest number of patients were seen in the age group 16-30 years and minimum number of patients were in the age group above 70 years. The youngest patient was an 11-month-old baby that presented with tinea corporis. The oldest patient was 78 years old and had tinea unguium affecting toes. Manual labourers were the occupational group most commonly affected and the commonest symptom noted by patients was itching (79.2\%). Occlusive dressing was noted in $72 \%$ patients and $3 \%$ patients gave a history of contact with pet animals. There was history of similar involvement in family members in $23 \%$ patients. The most common associated disease was found to be Diabetes Mellitus (13\%). The commonest clinical type observed was tinea corporis in 52 patients $(40 \%)$ and the least common was tinea faciei. All tinea capitis cases were male children. Fungal Culture was positive in $47 \%$ of patients. The most common species observed in the culture was Trichophyton rubrum (57.5\%), followed by Trichophyton mentagrophyte (29.5\%).

\section{REFERENCES}

1. Petmy LJ, Lando AJ, Kaptue L, et al. Superficial mycoses and HIV infection in Yaounde. J Eur Acad Deramtol Venereol 2004;18(3):301-4.

2. Emmons $\mathrm{CW}$, Binford $\mathrm{CH}, \mathrm{Utz}$, et al. Chapter 10 . Dermatophytosis. In: Medical mycology. Philadelphia: Lea and Febriger 1977:117-67.

3. Roderick JH. Chapter 267. Dermatophytosis and other superficial mycoses. In: Mandell, Douglas \& Bennett's principles and practices of infectious disease. $7^{\text {th }}$ edn. Philadelphia, Churchill Livingstone: Elsevier 2010:334555.

4. Kamothi MN, Patel BP, Mehta SJ, et al. Prevalence of dermatophyte infection in district Rajkot. Electronic Journal of Pharmacology and Therapy 2010;3:1-3.

5. Bindu V, Pavithran K. Clinico-mycological study of dermatophytosis in Calicut. Indian J Dermatol Venereol Leprol 2002;68(5):259-61.

6. Khalique A, Sengupta SR, Jhala HI, et al. Incidence and types of dermatomycoses in Aurangabad. Indian J Dermatol Venereol Leprol 1974;40(2):66-72.

7. Banerjee U, Sharma AK. A study of dermatophytosis in Delhi. Indian J Dermatol Venereol Leprol 1984;50(1): 41-4. 
8. Poria VC, Samuel A, Achary MK, et al. Dermatomycosis in and around Jamnagar. Indian J Dermatol Venereol Leprol 1981;47(2):84-7.

9. Amma SM, Paniker CK, Gopinathan T. Studies on dermatomycosis in Calicut (Kerala). Clinical and mycological investigations. Indian J Pathol Microbiol 1982;25(1):11-7.

10. Stephen S, Rao KN. Superficial mycoses in Manipal. Ind J Dermatol Venereol Leprol 1975;41:106-10 .

11. Hay RJ, Reid S, Talwat E, et al. Immune responses of patients with Tinea imbricata. $\mathrm{Br} J$ Dermatol 1983;108(5):581-6.

12. Nath P, Agarwal PK. Some observations on mycotic infections in Lucknow. Ind J Med Res 1971;59(5);675-82.

13. Martin AG, Kobayashi GS. Fungal diseases with cutaneous involvement. In: Dermatology in general medicine. Fitzpatrick TB, Eisem AZ, Wolff K, eds. 4th edn. New York: McGraw Hill 1993:2421-51.

14. Sentamilselvi G, Kamalam A, Ajithadas K, et al. Scenario of chronic dermatophytosis: an Indian study. Mycopathologia 1997-98;140(3):129-35.

15. Jagtap P, Grover S, Junnarkar RV. A clinical and mycological study of Tinea capitis in Nagpur. Ind J Dermatol Venereal Leprol 1972;38(1):21-6.

16. Elewski BE. Cutaneous mycoses in children. Br J Dermatol 1996;(134 Suppl 46):7-11.

17. Bronson DM, Desai DR, Barsky S, et al. An epidemic of infection with Trichophyton tonsurans revealed in a 20 year survey of fungal infections in Chicago. J Am Acad Dermatol 1983;8(3):322-30.

18. Rippon JW. Dermatophytosis and dermatomycosis. In: Wonsiewicz M. edr. Medical mycology. The pathogenic fungi and pathogenic actinomycetes. $3^{\text {rd }}$ edn. Philadelphia: WB Saunders 1988:167-25.
19. Amin AG, Shah Cf, Shah HS. Analysis of 141 cases of dermatophytosis. Ind J Dermatol Venereol Leprol 1971;37(4):123-8.

20. Rothman S, Smiljanic A. The spontaneous cure of tinea capitis in puberty. Journal Invest Dermatol 1947;8(2): 81-98.

21. Perea S, Ramos MJ, Garau M, et al. Prevalence and risk factors of tinea unguium and tinea pedis in the general population in Spain. Journal of Clinical Microbiology 2000;38(9):3226-30.

22. Weitzman, Padhye AA. Dermatophytes: gross and microscopic. Dermatologic Clinics 1996;14(1):9-22.

23. Jolly HW, Carpenter CL. Oral glucose tolerance studies in recurrent Trichophyton rubrum infections. Arch Dermatol 1969;100(1):26-8.

24. Jones HE. The atopic-chronic dermatophytosis syndrome. Act Derma Venereol (Stockholm) 1980;(Suppl 92):81-5.

25. Rongioletti F, Persi A, Tripodi S, et al. Proximal white subungual onychomycosis: a sign of immunodeficiency. J Am Acad Dermatol 1994;30(1):129-30.

26. Selvi SG, Kamalam A, Ajithados K, et al. Clinical and mycological features of dermatophytosis in renal transplant recipients. Mycoses 1999;42(1-2):75-8.

27. Dahl MV, Gramdo SA. Chronic dermatophytosis: what is special about Trichophyton rubrum? Adv Dermatol 1994;9:97-109.

28. Williams JV, Honig PJ, McGinley KJ, et al. Semiquantitative study of tinea capitis and the asymptomatic carrier state in inner-city school children. Pediatrics 1995;96(2 Pt 1):265-7. 